\title{
Diaphragmatic Ultrasound Assessment in Subjects With Acute Hypercapnic Respiratory Failure Admitted to the Emergency Department
}

\author{
Gianmaria Cammarota, Ilaria Sguazzotti, Marta Zanoni, Antonio Messina, Davide Colombo, \\ Gian Luca Vignazia, Luigi Vetrugno, Eugenio Garofalo, Andrea Bruni, Paolo Navalesi, \\ Gian Carlo Avanzi, Francesco Della Corte, Giovanni Volpicelli, and Rosanna Vaschetto
}

\begin{abstract}
BACKGROUND: Early identification of noninvasive ventilation (NIV) outcome predictors in patients with COPD who are experiencing acute hypercapnic respiratory failure consequent to exacerbation or pneumonia is a critical issue. The primary aim of this study was to investigate the feasibility of performing diaphragmatic ultrasound for excursion, thickness, and thickening fraction in highly dyspneic subjects with COPD admitted to the emergency department for exacerbation or pneumonia, before starting NIV (T0) and after the first (T1) and second hour (T2) of treatment. Secondarily, we determined whether these variables predicted early NIV failure. METHODS: Adult subjects with COPD admitted to the emergency department for exacerbation or pneumonia requiring NIV were eligible. Right-sided diaphragmatic excursion, bilateral thickness, thickening fraction, and arterial blood gas analyses were performed at T0, T1, and T2. Feasibility was estimated by considering the number of subjects whose diaphragmatic function could be evaluated at each time point. At T2, subjects were classified in 2 subgroups according to early NIV failure, which was defined as the inability to achieve a $\mathbf{p H} \geq 7.35$; the ability to achieve $\mathrm{pH} \geq 7.35$ indicated NIV success. RESULTS: Of the 22 subjects enrolled, 21 underwent complete diaphragm ultrasound evaluation (ie, right excursion and bilateral thickness at T0, T1, and T2) for a total of 63 excursion and 126 thickness assessments. At T2, 12 NIV successes and 9 NIV failures were recorded. Diaphragmatic excursion was greater in NIV successes than in NIV failures at T0 (1.92 [1.22-2.54] $\mathrm{cm}$ versus $1.00[0.60-1.41] \mathrm{cm}, P=.02)$, at $\mathrm{T} 1(2.14[1.76-2.77] \mathrm{cm}$ versus 0.93 [0.82$1.27] \mathrm{cm}, P=.007)$, and at $\mathrm{T} 2(1.99[1.63-2.54] \mathrm{cm}$ versus $1.20[0.79-1.41] \mathrm{cm}, P=.008)$, respectively. Diaphragmatic thickness and thickening fraction were similar in both groups. CONCLUSIONS: In our emergency department setting, diaphragm ultrasound was a feasible and reliable tool to monitor highly dyspneic acute hypercapnic respiratory failure subjects with COPD undergoing NIV. (ClinicalTrials.gov registration NCT03314883.) Key words: diaphragm; respiratory insufficiency; ultrasonography; noninvasive ventilation. [Respir Care 2019;64(12):1469-1477. (C) 2019 Daedalus Enterprises]
\end{abstract}

\section{Introduction}

Noninvasive ventilation (NIV) is commonly used, both in the emergency department and the ICU, as a first-line

Drs Cammarota, Zanoni, Colombo, and Vignazia are affiliated with the Department of Anesthesiology and Intensive Care, Maggiore della Carità University Hospital, Novara, Italy. Drs Sguazzotti, Avanzi, Della Corte, and Vaschetto are affiliated with the Department of Translational Medicine, Eastern Piedmont University, Novara, Italy. Dr Messina is affiliated with the Department of Anesthesiology and Intensive Care, Humanitas Research Hospital, Milan, Italy. Dr Vetrugno is affiliated with the intervention for patients with COPD who present with acute hypercapnic respiratory failure (AHRF) due to an exacerbation ${ }^{1-3}$ or community-acquired pneumonia. ${ }^{3,4}$ In most cases, patients who respond to NIV have an im-

Anesthesia and Intensive Care Clinic, Department of Medicine, University of Udine, Italy. Drs Garofalo, Bruni, and Navalesi are affiliated with Anesthesia and Intensive Care, Department of Medical and Surgical Sciences, Magna Graecia University, Catanzaro, Italy. Dr Volpicelli is affiliated with the Department of Emergency Medicine, San Luigi Gonzaga University Hospital, Torino, Italy. 
proved $\mathrm{pH}$ or breathing frequency within the first $1-4 \mathrm{~h}$ after NIV initiation. ${ }^{1}$ NIV in these patients has been shown

\section{See the Related Editorial on Page 1600}

to improve gas exchange, reduce the rate of endotracheal intubation, and improve survival. 2,5,6 Conversely, patients who do not respond to NIV, and thus require invasive ventilation, have worse clinical outcomes. ${ }^{7}$ Hence, it is advisable to look for NIV failure as early as $2 \mathrm{~h}$ after NIV initiation. ${ }^{8}$

In recent years, the assessment of diaphragm function with ultrasound has been increasingly investigated in the emergency department ${ }^{9-11}$ and during hospital stay. ${ }^{12,13} \mathrm{Di}$ aphragm ultrasound is a noninvasive and repeatable bedside tool, and it has no contraindications. ${ }^{12}$ Recent studies on subjects with COPD exacerbation suggested that a reduced diaphragm thickening fraction measured with ultrasound is a sign of diaphragmatic dysfunction, and that it may be useful to predict NIV failure, longer hospital stay, and higher mortality rate. ${ }^{10,11}$ However, in the aforementioned studies, diaphragmatic ultrasound was only assessed upon admission, before NIV application. Furthermore, it has been proposed that reduced ultrasound diaphragmatic excursion may be an indicator for NIV requirement in patients admitted to emergency department with acute dyspnea. ${ }^{9}$

Despite this growing body of evidence attesting to the utility of diaphragm ultrasound in predicting NIV outcome, it still remains unclear whether the assessment of diaphragmatic excursion and thickening fraction at multiple time points (ie, upon admission, at NIV initiation, and after 1 and $2 \mathrm{~h}$ of NIV) in dyspneic patients with COPD admitted to the emergency department is a feasible and meaningful clinical approach.

To address this issue, we performed this pilot study to evaluate the feasibility of performing diaphragmatic ultrasound to assess excursion, thickness, and thickening fraction in highly dyspneic subjects with COPD who were

\footnotetext{
A version of this paper was presented at the SMART Congress, held May 9-11, 2018, in Milan, Italy, and at the 2018 ESICM LIVES Congress, held October 20-24, 2018, in Paris, France.

The authors have disclosed no conflicts of interest.

Drs Cammarota and Sguazzotti contributed equally to this work.

Correspondence: Gianmaria Cammarota $\mathrm{MD} \mathrm{PhD}$, Department of Anesthesiology and Intensive Care, Maggiore della Carità University Hospital, Corso Mazzini 18, 28100, Novara, Italy. E-mail: gmcamma@gmail.com.
}

DOI: $10.4187 /$ respcare.06803

\section{QUICK LOOK}

\section{Current knowledge}

Noninvasive ventilation (NIV) is a well-established therapy for acute hypercapnic respiratory failure secondary to a COPD exacerbation or community-acquired pneumonia. Patients failing NIV and requiring endotracheal intubation have worse outcomes. To this end, it is imperative to determine reliable predictors of NIV failure.

\section{What this paper contributes to our knowledge}

Our results support the feasibility and usefulness of diaphragm ultrasound in the assessment of diaphragm function during NIV application for acute hypercapnic respiratory failure in an emergency department setting. Larger trials are needed to test the predictive value of diaphragm excursion relative to arterial $\mathrm{pH}$ and $\mathrm{P}_{\mathrm{aCO}_{2}}$ in the prediction of NIV failure.

admitted to the emergency department for exacerbation or pneumonia, before starting NIV and after the first and second hour of treatment (primary end point). The secondary aim was to assess whether diaphragmatic excursion, thickness, and thickening fraction can be used as predictors of early NIV failure.

\section{Methods}

\section{Study Population}

We conducted a pilot, observational cohort study at the emergency department of the Maggiore della Carità University Hospital in Novara, Italy, from October 2017 to April 2018. Our emergency department has an annual census of 56,000 visits of adult patients per year. The study was conducted according to the principles outlined in the Declaration of Helsinki, approved by the local ethical committee (protocol \#CE 112/17), and registered at www. clinicaltrials.gov. Written informed consent was obtained for all subjects according to local regulations.

All adult patients with COPD who were consecutively admitted to our emergency department for hypercapnic AHRF related to COPD exacerbation or pneumonia and requiring NIV were considered eligible. ${ }^{1}$ The exclusion criteria were use of NIV at home, AHRF due to overt cardiogenic pulmonary edema, history of interstitial lung disease (fibrosis), neuromuscular disease, significant chest wall deformities, previous diagnosis of diaphragmatic palsy, recent thoracotomy or sternotomy (within the previous year), severe hemodynamic instability or shock, in- 
tracranial hypertension, pregnancy, any major contraindication to NIV (including the need for immediate endotracheal intubation), or diagnosis of pneumothorax or pneumomediastinum.

\section{Study Protocol}

Upon admission to the emergency department, all eligible subjects underwent standard clinical evaluation and emergency treatment according to current best clinical practice. Before starting NIV (T0), an arterial blood gas (ABG) sample was drawn, followed by diaphragmatic ultrasound examination. NIV was then started, and diaphragmatic ultrasound and $\mathrm{ABG}$ analysis were repeated after $1 \mathrm{~h}$ (T1) and after $2 \mathrm{~h}$ (T2) of NIV.

\section{NIV Setting}

NIV was delivered through an oronasal or full-face mask connected to a high-performance ventilator (Servo-s Ventilator System, Maquet Critical Care, Solna, Sweden) in noninvasive pressure support mode. PEEP and delivered $\mathrm{F}_{\mathrm{IO}_{2}}$ were set to achieve a transcutaneous peripheral saturation target of $88-92 \% .{ }^{1}$ Pressure support level was adjusted to obtain a target volume of $6-8 \mathrm{~mL} / \mathrm{kg}$, a frequency $<30$ breaths/min, and air leak $<15 \%$. Cycling was set at $40 \%$ of peak flow. ${ }^{14}$

\section{Endotracheal Intubation}

The attending physician, blinded to the diaphragm ultrasound evaluation, determined if and when endotracheal intubation was required and directed the shift to invasive mechanical ventilation according to specific recommendations. ${ }^{1,15}$

\section{Measurements}

ABG analysis and dyspnea, assessed with a visual analog scale, were obtained at T0, T1, and T2. Dyspnea scores was recorded by physicians or nurses involved in a subject's care. The dyspnea visual analog scale was represented by a $20-\mathrm{cm}$ horizontal line. The ends were defined as the extreme limits of dyspnea from the left (lower end, best, "not at all breathless") to the right (upper end, worst, "extremely breathless"). Subjects were instructed to indicate on the line the point corresponding to their breathlessness perception. At each assessment, subjects were not reminded of their previous ratings. Upon admission, the following patient data were recorded: Glasgow Coma Scale, Sepsis-related Organ Failure Assessment (SOFA) score, Acute Physiology and Chronic Health Evaluation II (APACHE II) Score, and a prognostic score used for COPD exacerbation patients according to the age upon ad- mission, neutrophil count, and history of heart disease (NC85). ${ }^{16}$ Notes on medical history included acute dyspnea (ie, onset in the last $24 \mathrm{~h}$ ) and breathing frequency; past illness; use of tobacco (active or previous, quantified as pack-year); and medications, in particular corticosteroids, either systemic or inhaled. All subjects underwent chest radiography.

\section{Diaphragmatic Ultrasound}

Diaphragmatic ultrasound was performed at $\mathrm{T} 0, \mathrm{~T} 1$, and T2 to assess both excursion and thickness, using techniques previously described and validated. ${ }^{12,13}$ After the first evaluation, a cutaneous marker was applied to standardize probe placement and minimize measurement variability. ${ }^{13}$ Measurements were obtained at bedside with a portable ultrasound machine equipped with either a convex $(1.6-4.6 \mathrm{MHz})$ or a linear $(3.4-10.8 \mathrm{MHz})$ probe (Logic P6 Pro, GE Healthcare, Wauwatosa, Wisconsin); subjects were in a semirecumbent position. Diaphragmatic thickness measures were performed on both hemidiaphragms. Diaphragmatic excursion was evaluated on the right side because the small acoustic window provided by the spleen on the left side is limited by the rapid inspiratory lung movement of dyspneic subjects and the acoustic barrier of air inside the bowel and stomach. ${ }^{17,18}$ Diaphragmatic thickness was measured at both end-expiration and end-inspiration. Diaphragmatic thickening fraction, an indirect estimate of diaphragmatic effort, ${ }^{10,12,13,19}$ was calculated as follows: ${ }^{17}$

thickening fraction $(\%)=([$ inspiratory thickness

- expiratory thickness]/expiratory thickness) $\times 100$

In each subject, we performed 3 diaphragmatic excursion assessments on the right side and 3 expiratory and inspiratory thickness measurements on both sides. The mean values of diaphragmatic excursion and expiratory and inspiratory thickness were computed. Diaphragmatic ultrasound was performed by 2 investigators (GC, IS), who were blinded to ABG results. For each subject, all measurements were performed by one operator. Ultrasonographic and clinical data were recorded with a data collector independent of the groups of ultrasound operators and physicians involved in subject care.

\section{Ultrasound Operators' Variability}

Intra- and inter-observer variability of the 2 ultrasound operators was tested before enrollment. Each operator conducted diaphragmatic ultrasound evaluations for excursion and thickness in 10 ICU subjects undergoing invasive mechanical ventilation or NIV, for a total of 80 exams per 


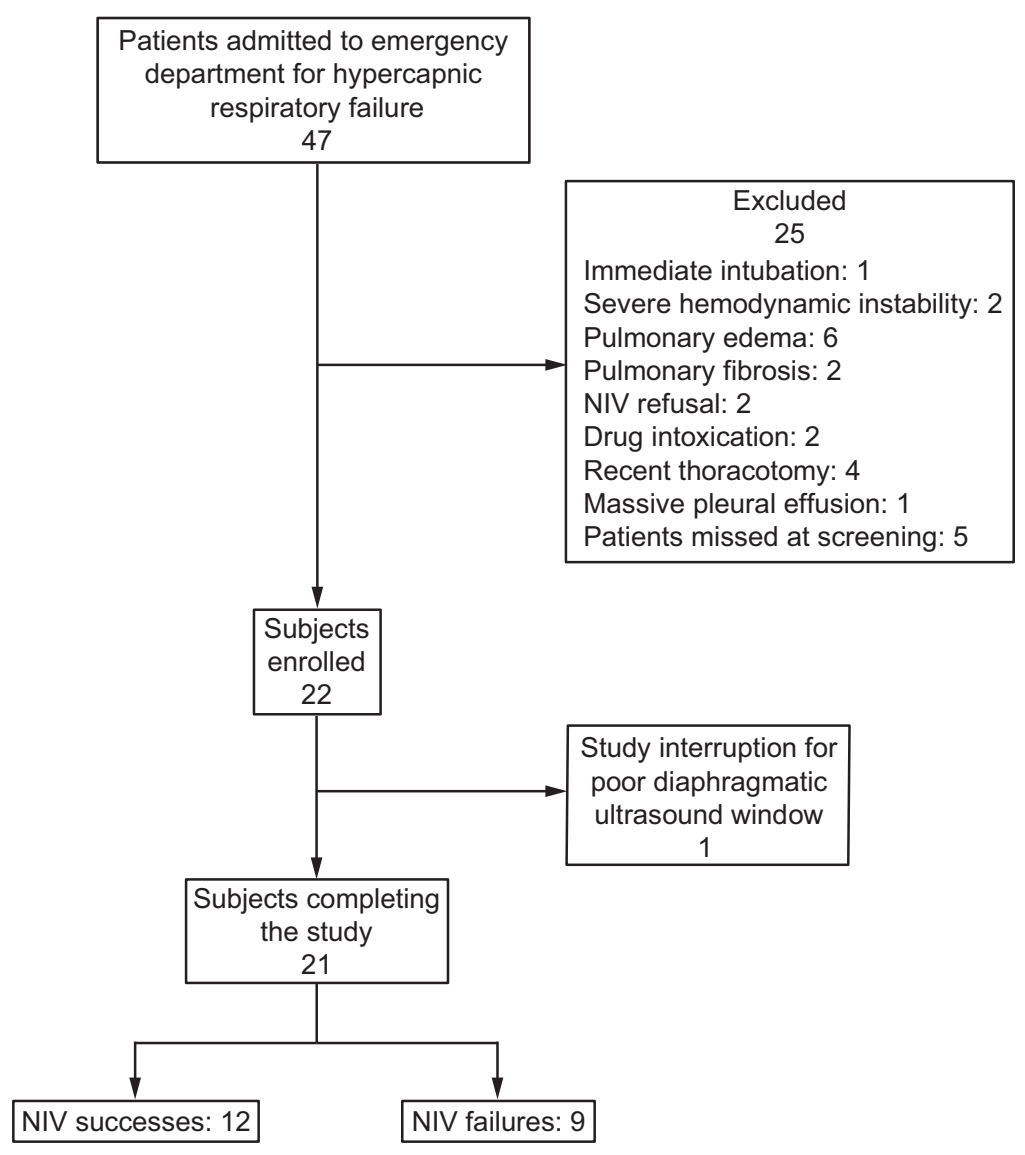

Fig. 1. Flow chart. NIV = noninvasive ventilation.

operator. ${ }^{20}$ The intraclass correlation coefficients measuring consistency and absolute agreement, the repeatability and reproducibility coefficients, and the standard error for inspiratory diaphragmatic thickness, expiratory diaphragmatic thickness, and diaphragmatic excursion were all computed to describe intra- and inter-observer variability of the ultrasound operators.

\section{Statistical Analysis}

In our emergency setting, a sample size of 21 subjects was considered adequate to evaluate diaphragmatic ultrasound feasibility in assessing diaphragmatic function within $2 \mathrm{~h}$ of NIV application, according to previous investigations. ${ }^{9,21}$ Subjects who completed the study were divided in 2 subgroups according to early NIV success or failure: NIV successes were those subjects able to reach a $\mathrm{pH} \geq 7.35$ at T2, and NIV failures were those subjects with persistent respiratory acidosis at $\mathrm{T} 2(\mathrm{pH}<7.35) .{ }^{6}$ Continuous variables were reported as median and interquartile range. Between-group comparison was assessed with the MannWhitney test and using the Holm-Sidak method correction. The Friedman test and the Dunn test correction were ap- plied for trend analysis. Categorical variables were evaluated with a Fisher exact test. Receiver operating characteristic analysis was used to investigate the accuracy of diaphragmatic ultrasound parameters, $\mathrm{pH}$, and $\mathrm{P}_{\mathrm{aCO}}$ at both $\mathrm{T} 0$ and $\mathrm{T} 1$ in predicting NIV failure and NIV success; area under the curve (AUC), 95\% CI, and $P$ values were also recorded. For all comparisons, $P<.05$ was considered significant. Statistical analysis was carried out using Prism 6.0 software (GraphPad, San Diego, California).

\section{Results}

In the study period, a total of 47 hypercapnic AHRF subjects were examined for eligibility, 22 of whom were enrolled (Fig. 1). In 21 subjects, we performed a complete diaphragmatic ultrasound evaluation, including both right excursion and bilateral thickness assessment during the first $2 \mathrm{~h}$ after emergency department admission, for a total of 63 excursion and 126 thickness measurements. In one subject, diaphragm ultrasound was interrupted due to insufficient visualization of the left hemidiaphragm. Subjects who completed the examination were then divided in 2 subgroups: 12 subjects were deemed NIV successes, and 
Table 1. Baseline Characteristics

\begin{tabular}{lccc}
\hline \hline \multicolumn{1}{c}{ Characteristics } & $\begin{array}{c}\text { NIV Success } \\
(n=12)\end{array}$ & $\begin{array}{c}\text { NIV Failure } \\
(n=9)\end{array}$ & $P$ \\
\hline Male & $5(42)$ & $3(33)$ & $>.99$ \\
Age, y & $79(70-83)$ & $85(73-86)$ & .27 \\
Body mass index, kg/m ${ }^{2}$ & $26(24-28)$ & $26(19-37)$ & .93 \\
SOFA score & $3(2-3)$ & $4(3-4)$ & .044 \\
APACHE II score & $20(18-21)$ & $20(18-21)$ & .80 \\
GCS score & $15(15-15)$ & $15(14-15)$ & .61 \\
NC85 & $1(1-2)$ & $1(0.5-2)$ & .85 \\
Sepsis & $1(8)$ & $1(11)$ & $>.99$ \\
Pneumonia & $4(33)$ & $4(44)$ & .67 \\
Acute dyspnea & $7(54)$ & $4(44)$ & .67 \\
Diabetes & $4(33)$ & $1(11)$ & .34 \\
Inhaled steroid use & $5(42)$ & $3(33)$ & .99 \\
Systemic steroid use & $6(50)$ & $3(33)$ & .66 \\
Active smoker & $4(33)$ & $3(33)$ & \\
& & & \\
Values are expressed as $n(\%)$ for dichotomous variables and as median (IQR) for continuous \\
variables.
\end{tabular}

Table 2. Ventilator Settings

\begin{tabular}{|c|c|c|c|}
\hline Parameters & NIV Success & NIV Failure & $P$ \\
\hline \multicolumn{4}{|l|}{$\mathrm{PEEP}, \mathrm{cm} \mathrm{H}_{2} \mathrm{O}$} \\
\hline $\mathrm{T} 1$ & $7(6-8)$ & $6(6-8)$ & .25 \\
\hline $\mathrm{T} 2$ & $7(5-8)$ & $8(6-8)$ & .35 \\
\hline \multicolumn{4}{|c|}{ Inspiratory $\mathrm{PS}, \mathrm{cm} \mathrm{H}_{2} \mathrm{O}$} \\
\hline $\mathrm{T} 1$ & $10(10-10)$ & $10(10-12)$ & .32 \\
\hline $\mathrm{T} 2$ & $10(10-11)$ & $10(10-13)$ & .20 \\
\hline \multicolumn{4}{|l|}{$\mathrm{V}_{\mathrm{T}}, \mathrm{mL} / \mathrm{kg}$} \\
\hline $\mathrm{T} 1$ & $7.2(6.2-8.0)$ & $7.2(6.3-7.9)$ & .99 \\
\hline $\mathrm{T} 2$ & $7.2(6.8-7.6)$ & $6.9(6.5-7.4)$ & .35 \\
\hline
\end{tabular}

Values are expressed as median (interquartile range).

$\mathrm{NIV}=$ noninvasive ventilation

Inspiratory PS $=$ support of pressure applied over PEEP during inspiration

$\mathrm{V}_{\mathrm{T}}=$ tidal volume on ideal body weight

9 subjects were regarded as NIV failures. General characteristics and clinical features of the study population are reported in Table 1 . The only difference observed between the subgroups was a lower SOFA score in NIV successes. As shown in Table 2, NIV ventilator parameters were similar in either group.

Diaphragmatic ultrasound measurements revealed a greater excursion in NIV successes compared to that observed in NIV failures at T0 $(P=.02)$, T1 $(P=.007)$, and T2 $(P=.008)$ (Table 3$)$. In addition, left-sided expiratory thickness of NIV successes at T2 was higher than that of NIV failures at the same time point $(P=.01)$. No differences were found between the subgroups in right and left inspiratory thickness, thickening fraction, and right expiratory thickness during the whole study period. Finally, no differences were detected in expiratory thickness, inspiratory thickness, and thickening fraction measured on both sides.

As depicted in Table 4, the $\mathrm{pH}$ was higher in NIV successes than in NIV failures at T1 and T2. Moreover, in NIV successes, the $\mathrm{pH}$ increased from $\mathrm{T} 0$ to $\mathrm{T} 1$ and from T0 to T2. By contrast, the same group displayed a decrease in $\mathrm{P}_{\mathrm{aCO}_{2}}$ from $\mathrm{T} 0$ to $\mathrm{T} 2$, whereas the $\mathrm{P}_{\mathrm{aO}}$ improved from T0 to T2. Breathing frequency was not different between the groups, although in NIV successes a reduction was observed from T0 to T2. Lastly, the dyspnea score improved from $\mathrm{T} 0$ to $\mathrm{T} 1$ and from $\mathrm{T} 0$ to $\mathrm{T} 2$ in NIV successes, whereas it only decreased from T0 to T2 in NIV failures.

Figure 2 presents the receiver operating characteristic analysis of diaphragmatic ultrasound excursion, $\mathrm{pH}$, and $\mathrm{P}_{\mathrm{aCO}_{2}}$ to predict NIV failure. Diaphragmatic ultrasound excursion at T1 (AUC $=0.98,95 \%$ CI 0.94-1.00, $P<.001$ ) was more accurate in predicting NIV response compared to $\mathrm{pH}(\mathrm{AUC}=0.89,95 \% \mathrm{CI} 0.75-1.00, P=.002)$ and $\mathrm{P}_{\mathrm{aCO}_{2}}(\mathrm{AUC}=0.76,95 \%$ CI $0.55-0.97, P=.03)$ at T1 and to diaphragmatic excursion $(\mathrm{AUC}=0.81,95 \% \mathrm{CI}$ $0.63-1.00, P=.007$ ) at T0. Left expiratory diaphragmatic thickness showed a good level of accuracy only at T2 (AUC $=0.83,95 \%$ CI 0.65-1.00, $P=.01$ ).

Table 5 presents clinical outcomes of the study population. No relevant differences were noticed between the groups with regard to clinical outcomes, except for NIV duration, which was shorter in NIV successes compared to NIV failures.

\section{Intra- and Inter-Observer Variability}

The intraclass correlation coefficients measuring consistency for inspiratory diaphragmatic ultrasound thickness, expiratory diaphragmatic thickness, and diaphragmatic excursion were $0.952,0.971,0.876$, respectively; the intraclass correlation coefficients measuring absolute agreement for these characteristics were 0.932, 0.963, 0.871 , respectively. Repeatability coefficients for inspiratory thickness, expiratory thickness, and excursion were $0.034,0.028,0.430$, respectively; reproducibility coefficients for these characteristics were 0.026, 0.016, 0.392, respectively. Finally, the standard errors of the mean for inspiratory diaphragmatic thickness, expiratory thickness, and excursion were $0.021 \mathrm{~cm}, 0.016 \mathrm{~cm}$, and $0.276 \mathrm{~cm}$, respectively. 


\section{Diaphragm Ultrasound In the EMERgEnCy DePARTMENT}

Table 3. Diaphragmatic Ultrasound Measurements

\begin{tabular}{|c|c|c|c|}
\hline Parameters & NIV Success & NIV Failure & $P$ \\
\hline \multicolumn{4}{|l|}{ Excursion, cm } \\
\hline T0 & $1.92(1.22-2.54)$ & $1.00(0.60-1.41)$ & .02 \\
\hline $\mathrm{T} 1$ & $2.14(1.76-2.77)$ & $0.93(0.82-1.27)$ & .007 \\
\hline $\mathrm{T} 2$ & $1.99(1.63-2.54)$ & $1.20(0.79-1.41)$ & .008 \\
\hline \multicolumn{4}{|c|}{$\begin{array}{l}\text { Right expiratory } \\
\text { thickness, cm }\end{array}$} \\
\hline T0 & $0.31(0.24-0.46)$ & $0.27(0.23-0.32)$ & .41 \\
\hline $\mathrm{T} 1$ & $0.33(0.25-0.38)$ & $0.22(0.21-0.24)$ & .10 \\
\hline $\mathrm{T} 2$ & $0.26(0.21-0.40)$ & $0.22(0.22-0.24)$ & .10 \\
\hline \multicolumn{4}{|c|}{$\begin{array}{l}\text { Right inspiratory } \\
\text { thickness, cm }\end{array}$} \\
\hline T0 & $0.54(0.40-0.73)$ & $0.42(0.38-0.45)$ & .17 \\
\hline $\mathrm{T} 1$ & $0.50(0.38-0.54)$ & $0.35(0.29-0.39)$ & .09 \\
\hline $\mathrm{T} 2$ & $0.40(0.33-0.62)$ & $0.32(0.31-0.40)$ & .15 \\
\hline \multicolumn{4}{|c|}{$\begin{array}{l}\text { Right thickening } \\
\text { fraction, } \%\end{array}$} \\
\hline T0 & $55.05(44.96-86.43)$ & $47.96(35.71-50.00)$ & .17 \\
\hline $\mathrm{T} 1$ & $41.00(37.98-75.70)$ & $41.18(39.68-62.50)$ & .48 \\
\hline $\mathrm{T} 2$ & $60.66(45.57-68.54)$ & $53.66(44.62-76.60)$ & .75 \\
\hline \multicolumn{4}{|c|}{$\begin{array}{l}\text { Left expiratory } \\
\text { thickness, cm }\end{array}$} \\
\hline T0 & $0.28(0.22-0.41)$ & $0.34(0.20-0.35)$ & .94 \\
\hline $\mathrm{T} 1$ & $0.28(0.24-0.45)$ & $0.20(0.20-0.25)$ & .039 \\
\hline $\mathrm{T} 2$ & $0.36(0.27-0.48)$ & $0.21(0.17-0-30)$ & .01 \\
\hline \multicolumn{4}{|c|}{$\begin{array}{l}\text { Left inspiratory } \\
\text { thickness }(\mathrm{cm})\end{array}$} \\
\hline T0 & $0.46(0.36-0.55)$ & $0.55(0.41-0.61)$ & .96 \\
\hline $\mathrm{T} 1$ & $0.41(0.35-0.69)$ & $0.33(0.27-0.36)$ & .055 \\
\hline $\mathrm{T} 2$ & $0.48(0.40-0.76)$ & $0.31(0.29-0.46)$ & .041 \\
\hline \multicolumn{4}{|c|}{$\begin{array}{l}\text { Left thickening } \\
\text { fraction }(\%)\end{array}$} \\
\hline T0 & $55.84(48.02-66.30)$ & $58.10(37.86-73.58)$ & .75 \\
\hline $\mathrm{T} 1$ & $48.24(35.95-67.58)$ & $44.90(40.54-59.30)$ & .71 \\
\hline $\mathrm{T} 2$ & $51.23(38.33-61.17)$ & $60.78(45.31-67.31)$ & .35 \\
\hline \multicolumn{4}{|c|}{$\begin{array}{l}\text { Values are expressed as median (interquartile range). Diaphragmatic ultrasound measurements } \\
\text { revealed a greater excursion in NIV successes compared to that observed in NIV failures at } \\
\text { T0 }(P=.02), \mathrm{T} 1(P=.007) \text {, and } \mathrm{T} 2(P=.008) \text {. In addition, left-sided expiratory thickness of } \\
\text { NIV successes at T2 was higher than that of NIV failures at the same time point }(P=.01) \text {. } \\
\text { No differences were found between the subgroups in right and left inspiratory thickness, } \\
\text { thickening fraction, and right expiratory thickness during the whole study period. Finally, no } \\
\text { differences were detected in expiratory thickness, inspiratory thickness, and thickening fraction } \\
\text { measured on both sides. } \\
\text { NIV = noninvasive ventilation }\end{array}$} \\
\hline
\end{tabular}

\section{Discussion}

There are 4 major findings of our study. First, repeated sonographic measurements of diaphragm thickness and excursion were feasible over time in subjects with COPD who were admitted to the emergency department for hypercapnic AHRF related to exacerbation or pneumonia. Second, diaphragmatic ultrasound excursion over the entire study period was greater in the NIV successes than in the NIV failure subjects. Third, in subjects with NIV success, left-sided diaphragmatic expiratory thickness im-
Table 4. Arterial Blood Gases, Breathing Frequency, and Dyspnea

\begin{tabular}{|c|c|c|c|}
\hline Parameters & NIV Success & NIV Failure & $P$ \\
\hline \multicolumn{4}{|l|}{$\mathrm{pH}$} \\
\hline T0 & $7.29(7.23-7.30)$ & $7.24(7.21-7.29)$ & .67 \\
\hline $\mathrm{T} 1$ & $7.34(7.32-7.38)+$ & $7.28(7.23-7.30)$ & .002 \\
\hline $\mathrm{T} 2$ & $7.36(7.35-7.39) \neq$ & $7.29(7.27-7.33)$ & $<.001$ \\
\hline \multicolumn{4}{|l|}{$\mathrm{P}_{\mathrm{aCO}_{2}}, \mathrm{~mm} \mathrm{Hg}$} \\
\hline T0 & $76.80(67.15-92.35)$ & $83.00(70.30-98.10)$ & .64 \\
\hline $\mathrm{T} 1$ & $58.80(51.30-74.65)$ & $81.30(65.40-95.20)$ & .049 \\
\hline $\mathrm{T} 2$ & $58.20(50.00-67.95)^{*}$ & $75.00(71.90-92.60)$ & .044 \\
\hline \multicolumn{4}{|l|}{$\mathrm{P}_{\mathrm{aO}_{2}}, \mathrm{~mm} \mathrm{Hg}$} \\
\hline T0 & $58.80(40.95-68.15)$ & $41.60(35.30-60.00)$ & .14 \\
\hline $\mathrm{T} 1$ & $64.40(59.05-71.15)$ & $66.60(56.90-74.00)$ & .68 \\
\hline $\mathrm{T} 2$ & $70.75(62.55-89.35)^{*}$ & $61.20(58.60-64.50)$ & .13 \\
\hline \multicolumn{4}{|c|}{$\begin{array}{l}\text { Breathing frequency, } \\
\text { breaths/min }\end{array}$} \\
\hline T0 & $30.6(25.7-35.5)$ & $28.9(20.9-36.8)$ & .67 \\
\hline $\mathrm{T} 1$ & $24.3(21.0-27.7)$ & $21.3(16.9-25.8)$ & .23 \\
\hline $\mathrm{T} 2$ & $21.1(17.5-24.7)$ ま & $20.2(15.7-24.8)$ & .74 \\
\hline \multicolumn{4}{|l|}{ Dyspnea score } \\
\hline T0 & $10.0(10.0-10.0)$ & $10.0(8.0-10.0)$ & .29 \\
\hline $\mathrm{T} 1$ & $5.5(3.5-7.0)^{*}$ & $6.0(4.0-7.0)$ & .49 \\
\hline $\mathrm{T} 2$ & $3.5(1.0-4.5) \ddagger$ & $4(3.0-6.0)^{*}$ & .38 \\
\hline $\begin{array}{l}\text { Values are expressed } \\
\text { * vs T0, } P<.05 . \\
\ddagger \text { vs T0, } P<.005 . \\
\text { NIV }=\text { noninvasive } \\
\text { Dyspnea score }=\text { vis }\end{array}$ & $\begin{array}{l}\text { dian (interquartile range). } \\
\text { ion } \\
\text { log scale dyspnea quantificati }\end{array}$ & & \\
\hline
\end{tabular}

proved at $\mathrm{T} 2$, whereas no changes over time were observed in NIV failures. Finally, diaphragmatic ultrasound excursion proved to be an early and accurate predictor of NIV outcome. Diaphragm ultrasound has been shown to be a reliable tool in evaluating diaphragmatic excursion and thickness in critically ill subjects with AHRF who are undergoing invasive mechanical ventilation. ${ }^{12,13}$ Recently, diaphragmatic ultrasound assessment has been proposed as a useful tool in managing patients with a COPD exacerbation who were admitted to the emergency department and are undergoing NIV. ${ }^{10,11}$ Furthermore, diaphragm ultrasound has been successfully used in subjects admitted to the emergency department with acute dyspnea. ${ }^{9}$ In this specific population, right-sided diaphragmatic ultrasound excursion measurement proved to be feasible and reproducible at both the intra- and inter-observer level..$^{9,22}$ In previous studies, ultrasound evaluations performed during NIV application occurred only upon admission, before starting NIV.

In agreement with previous reports, we have shown that diaphragm ultrasound is a feasible approach in subjects with hypercapnic AHRF who are admitted to the emergency department due to COPD exacerbation or pneumonia. However, unlike previous investigations, we performed ultrasound assessment not only at admission, but also over the first $2 \mathrm{~h}$ after NIV initiation. This procedure did not interfere with standard patient management in the emer- 

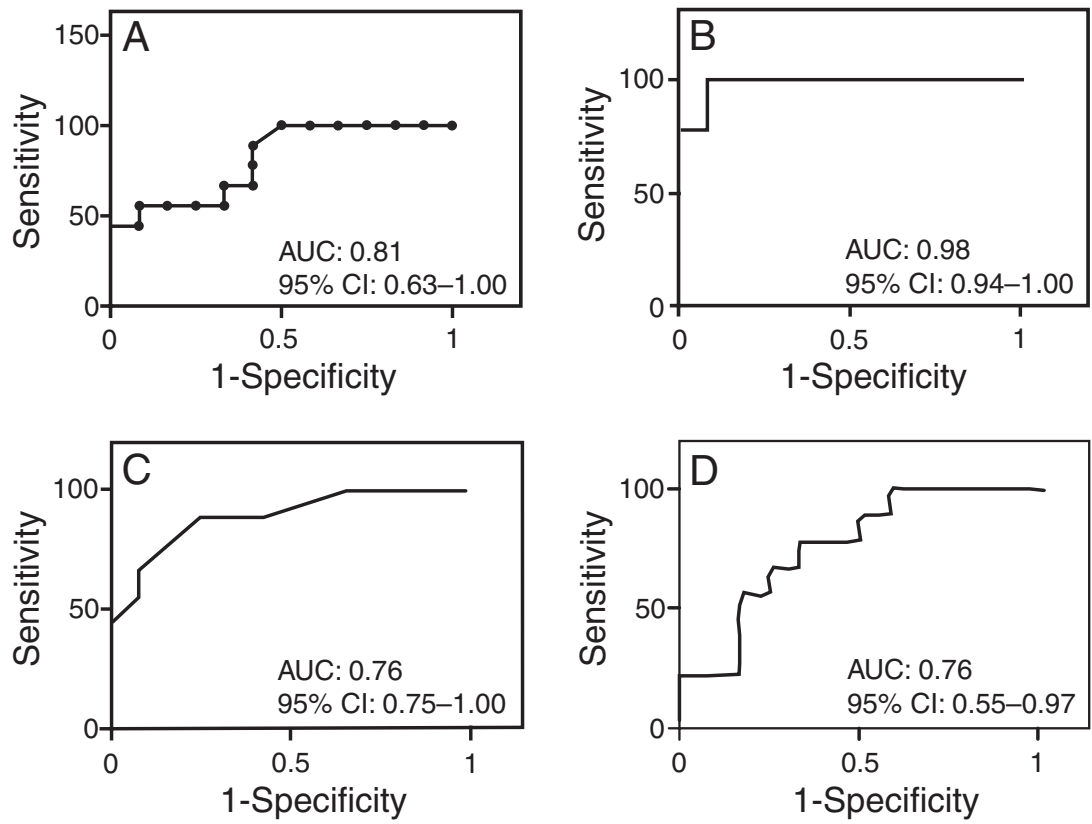

Fig. 2. Receiver operating characteristic analysis comparing predictors of NIV failure. A: Diaphragmatic ultrasound excursion at baseline before NIV application, B: diaphragmatic ultrasound excursion at $1 \mathrm{~h}$ after NIV application, C: arterial pH at $1 \mathrm{~h}$ after NIV application, and $\mathrm{D}$ : PaCO2 at $1 \mathrm{~h}$ after NIV application; TO = baseline; $\mathrm{T} 1=1 \mathrm{~h}$ after NIV application; AUC = area under the curve; NIV = noninvasive ventilation.

Table 5. Clinical Outcomes

\begin{tabular}{|c|c|c|c|}
\hline Outcomes & $\begin{array}{c}\text { NIV } \\
\text { Success }\end{array}$ & NIV Failure & $P$ \\
\hline $\begin{array}{l}\text { Emergency department } \\
\text { readmission* }\end{array}$ & $6(50)$ & $3(33)$ & .41 \\
\hline NIV duration, d & $1.5(1-2)$ & $4(2-5.5)$ & .004 \\
\hline Endotracheal intubation & 0 & 0 & \\
\hline Hospital stay, d & $9(5.8-14.3)$ & $6(4.5-9)$ & .14 \\
\hline In-hospital mortality & $1(8)$ & $2(18)$ & .55 \\
\hline 28-d mortality & $1(8)$ & $2(18)$ & .55 \\
\hline 90-d mortality & $4(33)$ & $2(18)$ & .66 \\
\hline \multicolumn{4}{|c|}{$\begin{array}{l}\text { Values are expressed as } n(\%) \text { for dichotomous variables and as median (IQR) for continuous } \\
\text { variables. NIV Success: } n=12 \text { subjects; NIV Failure: } n=9 \text { subjects. } \\
\text { * Subjects who required emergency department readmissions. } \\
\text { NIV = noninvasive ventilation }\end{array}$} \\
\hline
\end{tabular}

gency department because diaphragmatic ultrasound evaluation was carried out by a dedicated ultrasound examiner who was not directly involved in the subject's care. It is noteworthy that the diaphragmatic evaluation was assessed by 2 ICU physicians who regularly conduct ultrasound and were previously tested for intra-observer and inter-observer concordance, yielding a high level of agreement. Furthermore, the diaphragm evaluation procedure was hastened and simplified by applying a cutaneous marker, as previously reported. ${ }^{23}$

Diaphragmatic ultrasound excursion and thickness have been shown to be variously affected in subjects admitted to the emergency department with AHRF.9-11 In subjects with acute dyspnea admitted to the emergency department, a diaphragmatic ultrasound excursion $<2.3 \mathrm{~cm}$ was associated with a need for NIV. ${ }^{9}$ A marked reduction in diaphragmatic ultrasound excursion may be consequent to weaning failure, causing prolonged duration of invasive mechanical ventilation. ${ }^{24,25}$

In this study, we assessed diaphragmatic ultrasound excursion on the right hemidiaphragm and thickness bilaterally. In keeping with previous works conducted in different settings, $9,24,26$ we found a smaller diaphragmatic ultrasound excursion in NIV failures compared to NIV successes. Of note, this diaphragmatic excursion difference was observed despite having set noninvasive inspiratory pressure support so as to achieve a similar target tidal volume in both subgroups. As previously described, the relationship between diaphragmatic excursion and tidal volume appears to depend on the activation pattern of both the diaphragm and the accessory inspiratory muscles in healthy subjects. ${ }^{27}$ In our study population, we did not record respiratory inductance plethysmography, electromyograms of the different respiratory muscles, or clinical assessment of the chest wall (eg, Hoover's sign). Consequently, we can only speculate that, in NIV successes, there is a more marked diaphragm activity with respect to accessory inspiratory muscles, leading to a difference in diaphragmatic excursion between the subgroups. 
Our data also show that the left expiratory diaphragmatic thickness of NIV successes increases at T2, whereas that of NIV failures remains unchanged over the whole study period. In considering previous findings, we must take into account the side-by-side variability in hemidiaphragmatic movements, as previously reported. ${ }^{28}$ Moreover, due to the lack of data related to lung volume and air-trapping quantification, we can only speculate that in NIV successes, following improvement in dynamic hyperinflation, the diaphragm gains a more advantageous position, thereby increasing its expiratory thickness. This hypothesis would be in line with previous findings that indicate reduced expiratory diaphragmatic thickness with increased lung volumes secondary to dynamic hyperinflation in subjects with COPD. ${ }^{29}$ In fact, in the presence of dynamic hyperinflation, sustaining both a reduction in the area of diaphragm-lung apposition and a shift in the alignment of the diaphragmatic fibers from axial to radial, the diaphragm has been shown to work under unfavorable conditions, especially in acute settings. ${ }^{30,31}$

Using diaphragm ultrasound to assess diaphragm dysfunction through diaphragmatic thickening fraction depression has been demonstrated to be more accurate in predicting NIV outcome compared to baseline $\mathrm{pH}$ and early $\mathrm{P}_{\mathrm{aCO}}$ variations. ${ }^{10}$ In keeping with previous work, we report that diaphragm ultrasound, especially diaphragmatic excursion, unlike $\mathrm{pH}$ and $\mathrm{P}_{\mathrm{aCO}}$, is an early and accurate predictor of NIV outcome. Moreover, at $1 \mathrm{~h}$ after NIV application, diaphragmatic excursion sharply increases its accuracy and remains a more reliable predictor than $\mathrm{pH}$ and $\mathrm{P}_{\mathrm{aCO}}$.

This pilot study has several limitations. First, this was a single-center study investigating diaphragm ultrasound feasibility in hypercapnic AHRF subjects. Although our sample size is in line with previous work, ${ }^{9,21}$ our conclusions must be confirmed in future studies carried out in similar clinical settings. Second, our diaphragm ultrasound assessment was only performed in the first $2 \mathrm{~h}$ of NIV application, as previously suggested. ${ }^{8}$ It is worth noting that, in another investigation, a longer period of NIV application has been proposed, reaching up to $4 \mathrm{~h} .^{32}$ Therefore, future investigations should assess the predictive value of diaphragm ultrasound over a longer period of time. Third, our investigation evaluated diaphragmatic ultrasound in subjects with COPD experiencing exacerbation or pneumonia. In this regard, several studies have shown that, in subjects with COPD, pneumonia is characterized by higher hospitalization and ICU admission rates compared to exacerbation. ${ }^{33,34}$ Thus, specific studies addressing diaphragm ultrasound monitoring in these 2 populations must be undertaken to better assess diaphragmatic function with regard to clinical outcomes. Fourth, our study only assessed right diaphragmatic excursion. This was decided a priori because, in the acute setting, left diaphragmatic ultrasound excursion is difficult to investigate. ${ }^{22}$ Fifth, it has been reported that the diaphragm surface is characterized by several defects and irregularities, particularly in patients in the seventh and eighth decades of life who have pulmonary emphysema. ${ }^{35}$ Hence, a certain degree of variability must be taken in account when interpreting our data. Finally, early management of patients with hypercapnic AHRF who undergo NIV differ between hospital organizations and depending on the NIV expertise of the physician in charge.

Future multi-center studies are required to confirm our findings and to assess the best diaphragm ultrasound excursion cut-off value to predict NIV outcome in subjects admitted for hypercapnic AHRF related to COPD exacerbation.

\section{Conclusion}

In our setting, diaphragm ultrasound was a feasible and reliable clinical approach for assessing diaphragm dysfunction in dyspneic hypercapnic AHRF subjects undergoing NIV. Diaphragmatic excursion assessment $2 \mathrm{~h}$ after NIV initiation was a better predictor of NIV failure than $\mathrm{pH}, \mathrm{P}_{\mathrm{aCO}}$, and left expiratory diaphragmatic thickness. However, further larger multicenter clinical trials are needed to confirm the preliminary results of this pilot study.

\section{REFERENCES}

1. Rochwerg B, Brochard L, Elliott MW, Hess D, Hill NS, Nava S, et al. Official ERS/ATS clinical practice guidelines: noninvasive ventilation for acute respiratory failure. Eur Respir J 2017;50: 1-20.

2. Brochard L, Mancebo J, Wysocki M, Lofaso F, Conti G, Rauss A, et al. Noninvasive ventilation for acute exacerbations of chronic obstructive pulmonary disease. N Engl J Med 1995;333:817822 .

3. Squadrone E, Frigerio P, Fogliati C, Gregoretti C, Conti G, Antonelli $\mathrm{M}$, et al. Noninvasive vs invasive ventilation in COPD patients with severe acute respiratory failure deemed to require ventilatory assistance. Intensive Care Med 2004;30:1303-1310.

4. Confalonieri M, Potena A, Carbone G, Porta R, Tolley E, Meduri G. Acute respiratory failure in patients with severe community-acquired pneumonia: a prospective randomized evaluation of noninvasive ventilation. Am J Respir Crit Care Med 1999;160:1585-1591.

5. Ambrosino N, Vagheggini G. Noninvasive positive pressure ventilation in the acute care setting: where are we? Eur Respir J 2008; 31:874-886.

6. Vitacca M, Ambrosino N, Clini E, Porta R, Rampulla C, Lanini B, Nava S. Physiological response to pressure support ventilation delivered before and after extubation in patients not capable of totally spontaneous autonomous breathing. Am J Respir Crit Care Med 2001;164:638-641.

7. Chandra D, Stamm JA, Taylor B, Ramos RM, Satterwhite L, Krishnan JA, et al. Outcomes of noninvasive ventilation for acute exacerbations of chronic obstructive pulmonary disease in the United States, 1998-2008. Am J Respir Crit Care Med 2012;185:152-159. 


\section{Diaphragm Ultrasound In the EMERgEnCy DePARTMENT}

8. Vaschetto R, Longhini F, Navalesi P. Acute non-invasive ventilation. ERS Monogr 2016;74:186-199.

9. Bobbia X, Clément A, Claret PG, Bastide S, Alonso S, Wagner P, et al. Diaphragmatic excursion measurement in emergency patients with acute dyspnea: toward a new diagnostic tool? Am J Emerg Med 2016;34:1653-1657.

10. Marchioni A, Castaniere I, Tonelli R, Fantini R, Fontana M, Tabbì $\mathrm{L}$, et al. Ultrasound-assessed diaphragmatic impairment is a predictor of outcomes in patients with acute exacerbation of chronic obstructive pulmonary disease undergoing noninvasive ventilation. Crit Care 2018;22:1-9.

11. Antenora F, Fantini R, Iattoni A, Castaniere I, Sdanganelli A, Livrieri $\mathrm{F}$, et al. Prevalence and outcomes of diaphragmatic dysfunction assessed by ultrasound technology during acute exacerbation of COPD: a pilot study. Respirology 2017;22:338-344.

12. Matamis D, Soilemezi E, Tsagourias M, Akoumianaki E, Dimassi S, Boroli F, et al. Sonographic evaluation of the diaphragm in critically ill patients. Technique and clinical applications. Intensive Care Med 2013;39:801-810.

13. Goligher EC, Laghi F, Detsky ME, Farias P, Murray A, Brace D, et al. Measuring diaphragm thickness with ultrasound in mechanically ventilated patients: feasibility, reproducibility and validity. Intensive Care Med 2015;41:642-649.

14. Moerer O, Harnisch L-O, Herrmann P, Zippel C, Quintel M. Patientventilator interaction during noninvasive ventilation in simulated COPD. Respir Care 2016;61:15-22.

15. Davidson AC, Banham S, Elliott M, Kennedy D, Gelder C, Glossop A, et al. BTS/ICS guideline for the ventilatory management of acute hypercapnic respiratory failure in adults. Thorax 2016;71(Suppl 2): ii1-ii35.

16. Sainaghi PP, Colombo D, Re A, Bellan M, Sola D, Balbo PE, et al. Natural history and risk stratification of patients undergoing noninvasive ventilation in a non-ICU setting for severe COPD exacerbations. Intern Emerg Med 2016;11:969-975.

17. Vivier E, Dessap AM, Dimassi S, Vargas F, Lyazidi A, Thille AW, Brochard L. Diaphragm ultrasonography to estimate the work of breathing during non-invasive ventilation. Intensive Care Med 2012; 38:796-803.

18. Dinino E, Gartman EJ, Sethi JM, McCool FD. Diaphragm ultrasound as a predictor of successful extubation from mechanical ventilation. Thorax 2014;69:423-427.

19. Kim WY, Suh HJ, Hong SB, Koh Y, Lim CM. Diaphragm dysfunction assessed by ultrasonography: influence on weaning from mechanical ventilation. Crit Care Med 2011;39:2627-2630.

20. Kim H-Y. Statistical notes for clinical researchers: evaluation of measurement error 1: using intraclass correlation coefficients. Restor Dent Endod 2013;38:98.

21. Julious SA. Sample size of 12 per group rule of thumb for a pilot study. Pharm Stat 2005;4:287-291.
22. Boussuges A, Gole Y, Blanc P. Diaphragmatic motion studied by M-mode ultrasonography. Chest 2009;135:391-400.

23. Goligher EC, Dres M, Fan E, Rubenfeld GD, Scales DC, Herridge MS, et al. Mechanical ventilation-induced diaphragm atrophy strongly impacts clinical outcomes. Am J Respir Crit Care Med 2018;197: 204-213.

24. Palkar A, Narasimhan M, Greenberg H, Singh K, Koenig S, Mayo P, Gottesman E. Diaphragm excursion-time index: a new parameter using ultrasonography to predict extubation outcome. Chest 2018; 153:1213-1220.

25. Fayed AM, Barakat MS, Zakaria EM. Diaphragmatic dysfunction evaluation using ultrasonography as a predictor of weaning of patients with acute exacerbation of chronic obstructive pulmonary disease from mechanical ventilation. J Med Sci Clin Res 2013;04: 10950-10956.

26. Yoo JW, Lee SJ, Lee JD, Kim HC. Comparison of clinical utility between diaphragm excursion and thickening change using ultrasonography to predict extubation success. Korean J Intern Med 2018; 33:331-339.

27. Cohen E, Mier A, Heywood P, Murphy K, Guz A, Boultbee J. Excursion-volume relation of the right hemidiaphragm measured by ultrasonography and respiratory airflow measurements. Thorax 1994; 49:885-889

28. Houston JG, Cowan MD, McMillan NC, Angus RM, Thomson NC. Ultrasound assessment of normal hemidiaphragmatic movement: relation to inspiratory volume. Thorax 1994;49:500-503.

29. Smargiassi A, Inchingolo R, Tagliaboschi L, Di Marco Berardino A, Valente S, Corbo GM. Ultrasonographic assessment of the diaphragm in chronic obstructive pulmonary disease patients: relationships with pulmonary function and the influence of body composition - a pilot study. Respiration 2014;87:364-371.

30. Troyer AD, Wilson TA. Action of the diaphragm on the rib cage. J Appl Physiol (1985) 2016;121:391-400.

31. Decramer M. Hyperinflation and respiratory muscle interaction. Eur Respir J 1997;10:934-941.

32. Plant PK, Owen JL, Elliott MW. Non-invasive ventilation in acute exacerbations of chronic obstructive pulmonary disease: long term survival and predictors of in-hospital outcome. Thorax 2001;56:708-712.

33. Rello J, Rodriguez A, Torres A, Roig J, Sole-Violan J, GarnachoMontero $\mathrm{J}$, et al. Implications of COPD in patients admitted to the intensive care unit by community-acquired pneumonia. Eur Respir J 2006;27:1210-1216.

34. Menéndez R, Ferrando D, Vallés JM, Martínez E, Perpiñá M. Initial risk class and length of hospital stay in community-acquired pneumonia. Eur Respir J 2001;18:151-156.

35. Caskey C, Zerhouni E, Fishman E, Rahmouni A. Aging of the diaphragm: a CT study. Radiology 1989;171:385-389.

This article is approved for Continuing Respiratory Care Education credit. For information and to obtain your CRCE

(free to AARC members) visit

www.rcjournal.com

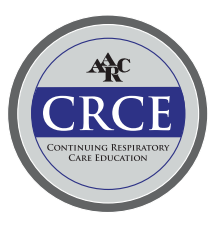

